\title{
Correlation of Ethical Conduct within an Organisation with the Absence of Employees from
} Work

\author{
Jernej Buzeti \\ Faculty of Administration, University of Ljubljana, Slovenia \\ jernej. buzeti@fu. uni-lj. si
}

Maja Klun

Faculty of Administration, University of Ljubljana, Slovenia

maja.klun@fu. uni-lj.si

Janez Stare

Faculty of Administration, University of Ljubljana, Slovenia

janez.stare@fu.uni-lj. si

Abstract

\begin{abstract}
The working environment of an organization in which employees perform their activities is a social system. It creates certain employee attitudes that are greatly influenced by the organisational or working culture and norms and the work ethics they define. The latter is actualised in certain organisational rules and standards and the manners and methods of employee communication and conduct. All aspects of conduct are relevant to employees, as behaviour directly influences the development of an (in)appropriate attitude to norms and working culture and, consequentially, also to absence of employees from work. Ethical conduct of employees is closely linked to the "strength" of the work ethic in an organisation and an analysis of studies shows that this is important also from the perspective of employee absence. This fact is confirmed by numerous studies that explain the statistical relationship between work ethics and employee absence. The INODEL study also used certain questions to establish the moral-ethical relationship of employees in Slovenia to medical absenteeism. On the one hand, the study checked whether employees ever abused sick leave and to what extent. On the other hand, the study sought to establish whether employees showed a moral-ethical attitude to work and performed their duties despite the fact that they could have been absent from work due to illness, injury or care for a family member. This article therefore presents certain results of the INODEL study that was performed among employees in the Republic of Slovenia.
\end{abstract}

Keywords: absenteeism, organizational culture, work ethic, ethical conduct

\section{Introduction}

An organisation is a social formation of persons (employees) and in every social system there are daily relationships between employees that give rise to various behaviours that can, firstly, influence the workplace mood and motivation of employees, or secondly, hinder employees in their work or create negative emotions that can result in improper behaviour.

Employee behaviour is influenced by different stimuli occurring in the external environment. Employees detect environmental influences and respond to them with their organisms. Such employee reactions to environmental stimuli and resulting behaviour differ widely. It is, however, a fact that the behaviour of an individual is substantially influenced also by their convictions regarding what is right and wrong (evil), what is allowed and prohibited.

The conduct of employees in a work environment is greatly dependent on personal and organisational values that influence the culture of behaviour or the (un)ethical conduct of employees. Musek (1993) believes that values serve as »a kid of signpost for morality and ethics«. Moorhead and Griffin (1998) explain that the ethic of an individual is their personal 
conviction on what is right and wrong or what is good and what bad. Cummings and Worley (2001) believe that ethics represent the standards of desired conduct of employees in a certain area.

Rubin et al. (1994) explain that work ethics of employees are an important social stimulus for the creating an in-group. Work ethics can be defined as a collection of values and behaviour related to the work place that people feel are moral. In general, work ethics are called strong if they feel that they have to fulfil all the formal responsibilities that come with a job, and called weak or low if people are more tolerant to the fulfilment of formal responsibilities.

Ethical conduct in an organisation, which also represents the state of affairs and degree of organisational culture, ${ }^{1}$ is tightly linked also to employee behaviour with regard to employee conduct in choosing whether to be absent from work and the reasons for such an absence.

There are a number of definitions of absence of employees from work or so-called absenteeism and different authors use different ${ }^{2}$ scopes to interpret the dimensions of absenteeism. Savery et al. (1998, p. 315) feel that absenteeism is defined as the absence of an employee from work. Yet they do not accurately state the type ${ }^{3}$ of absence in question. A similar stance is adopted by Eggert (2009), who emphasises that absence from work is linked to the lack of presence of an employee at work at a time when work is available. Lokke et al. (2007, p. 19) explain absenteeism as »a lack of physical presence of an employee at a certain location and in a time when social expectations dictate that the employee would be present at that location and at that time«. Briner (1999, p. 875) sees absenteeism simply as absence of an employee from work, but believes that it is very difficult to explain such an occurrence due to its complexity.

Employees can be absent from work voluntarily, but also involuntarily, meaning that their reasons for absence may be made up or wilfully fake. Such a view of absenteeism is linked to »black absenteeism«, which Sanders $(2004$, p. 138) and Van Dierendock et al. (2002) see as the form of absence from work that negatively influences the conduct of employees in an organisation as it is defined as an »anti-cooperative« form of behaviour.

The conduct of employees within an organisation is monitored, seen and felt by other employees, particulary in cases of unethical conduct. Evans and Palmer (2000) also emphasize certain perspectives that arise from the working environment and represent a potential cause for the absence of employees from work. Such perspectives include the factor of work culture and norms and the related aspect of work ethics.

The manner of conduct present in an organisation or among employees in an important factor as it can decisively influence the behaviour of an entire group. Employees ${ }^{4}$ naturally receive certain queues on how to behave and what behaviour is acceptable in the organisation from their peers. People can quickly establish which rules must be observed in practice and which can be ignored. Such conduct of employees is also the result of norms and working culture or ethics in an organisation, and it also influences decisions of employees regarding their absence from work. This is confirmed by Evans and Palmer (2000) who believe that the influence of norms present in an organisation is linked to the absence of employees from work. They emphasise that the development of norms or appropriate behaviour is not influenced only by words, but also by actions, particularly those of the management staff. This is shown also in the case of absence of employees from work. If certain absences of employees were overlooked in the past and not treated appropriately by the management, there is a high probability that such absences will continue in the future.

Further confirmation is seen in the study of Prottas (2008, p. 318), who emphasises the importance of the role of leaders in ethical conduct in organisations or construction of appropriate "standards" of conduct of leaders and employees as it is clear that the lowering of criteria or level of admissibility and appropriacy influences further conduct of employees.

\footnotetext{
${ }^{1}$ Organisational culture is a pattern of convictions and expectations of the members of an organisation and it sets out the norms that guide the behaviour of employees and groups within that organization (Fitzgerald and Desjardins, 2004). Organisational culture is a complete system of norms, values, ideas, convictions and symbols that set out the manner of behaviour and response to the issues of employees, thereby shaping the incident form of the organisation (Rozman et al., 1993).

${ }^{2}$ Allebeck and Mastekaasa (2004, p. 28) explain that employee absence is studied by a number of sciences including medicine, sociology, psychology, economics and organisation from their respective viewpoints.

${ }^{3}$ Definitions can be understood very generally as it is not clearly decided whether absence is a result of annual leave, health issues, etc. ${ }^{4}$ We believe that new employees seek rapid acceptance by their colleagues and accordingly adapt their behaviour at least partly, if not in whole, to the behaviour present among employees in the relevant organisation. Such behaviour depends on the norms and the organisational and working culture present in the organisation.
} 
The role of ethical conduct of employees in an organisation is not important only due to the fact that it showcases the appropriate level of culture in that organisation and serves as a model of appropriate behaviour, but also due to the fact that studies ${ }^{1}$ show the correlation between the ethical conduct of employees and employee absence.

A study carried out by Van Yperen et al (1994) established that a stronger (more strict) work ethic in an organisation results in a lower absence of employees from work. A similar result was observed in the study of Sanders (2004, p. 1145-150) which showed that a stronger (more strict) work ethic ${ }^{2}$ in an organisation (group of employees) lowers the rate of short absences of employees from work. These two variables are also linked to the cohesion of teams in the organisation. Results therefore show that work ethics are an important determinant in the creation of cohesion among employees and may influence employees to reduce their absence from work since their high ethical standards may lead them to be uncomfortable and reduce absences. The study of Guerts (1991, p. 385-398) et al showed that in a group of bus drivers with strong cohesion and connections between group members perceived absence from work as strongly undesirable and inappropriate. This was the reason for group members to avoid absence from work as a sign of respect, honesty towards each other and strong cohesion.

The study of De Boer (2002, p. 181-197) et al focused on the connections between »unfairness « ${ }^{3}$ at work and absence from work. The starting premise of the study was that a sense of unfairness at the workplace has an important role in the conduct of employees at work. Prior to carrying out their own research, the authors reviewed other studies and found that a detection (sense) of fairness and correctness of employees at work is linked to less frequent absences from work in comparison to those employees that sense relative unfairness in their workplace. Results of the study showed that perceived unfairness at the workplace influences the health of employees and has a direct influence on the absence of employees from work. The study also showed that a sense of unfair treatment at the workplace influences the development of psychosomatic illnesses.

Employees often look up to their direct superior and in the course of his study, Prottas (2008, p. 313-322) researched whether there is a link between the absence of employees from work and detection of (un)ethical conduct of the direct superior ${ }^{4}$. Results of the study showed that there is a negative correlation between the perception of improper behaviour of direct superiors and stress, poor health and absence of employees from work. Based on the results of studies of correlations between ethical conduct in an organisation and the absence of employees from work we can see that if standards of the culture of conduct and work ethics in an organisation are low, this can be reflected in a high degree of absence of employees from work which, in the opinion of Gardiner (1992, p. 290), is one of the most common issues management has to deal with.

The article thus has the following goals: (a) to present the importance of ethical conduct of employees in managing employee absence; and (b), to present results of the INODEL in the section related to establishing whether employees have abused absence from work to stay at home even though they were able to work. The fundamental purpose of this article is to use theoretical and empirical results to show the correlation between ethical conduct of employees and absence from work.

Two hypotheses were developed from the goals and purpose of the study, as follows:

- $\quad \mathrm{H} 1$ : Over 20 percent of employees that took part in the study were absent for medical reasons in the last 12 months, even though they could have performed their work.

- $\quad \mathrm{H} 2$ : In the last 12 months, over 50 percent of employees that took part in the study continued to perform their work even though they experienced injuries or illnesses that could enable them to gain medical leave, because they felt and knew that is appropriate for them to continue working.

\footnotetext{
1 See studies Prottas (2008), Sanders (2004), Fitzgerald and Desjardins (2004), Martoccio and Jimeno (2003), De Boer et al. (2002).

2 Sanders (2004, p. 139) defined work ethics as »the entirety of values and knowledge at the work position where people feel responsibility, morality and respect. Work ethics are strong if people feel they need to fulfil all formal work related responsibilities. Work ethics are weak/low if people are more tolerant towards fulfilment of formal work related responsibilities."

${ }^{3}$ Fairness at the workplace was interpreted as a combination of certain convictions and the sense of employees that their benefits (effects) in the work process are fair and correctly realised with regard to fulfilled criteria (fulfilled work tasks and other obligations). ${ }_{4}$ »Perceived Behavioral Integrity« (PBI) was intepreted by Prottas (2008) as a type of employee perception in which the actor (e.g. leader) behaves in a manner consistent with his/her statements regarding the observation of values, priorities, expectations and style of leadership.
} 
- H3: There is a correlation between a fair attitude of management personnel and the number of days of employee absence.

The structure of the present article first presents the aspect of the correlation of ethics in the working environment or ethical behaviour of employees and employee absence. The second section of the article presents the results of the INODEL study pertaining to the aspect of ethical conduct of employees (abuse of medical leave, assessment of honesty of management personnel by employees, etc. ). In the final section, the authors provide their view of the impact and role of ethical behaviour or culture of conduct in a working environment with regard to absence of employees from work.

\section{Methods}

The INODEL ${ }^{1}$ project included two studies that researched several ${ }^{2}$ areas. One of these areas was the area of health absenteeism with particular emphasis on the aspect of ethical behaviour of employees. The target group of the study consisted of employees employed in Slovenian organisations. Data collection was performed using the $\mathrm{CAWl}^{3}$ method and a questionnaire filled out by all subjects invited to participate in the study via an electronic invite. Here we present some of the results of the first study.

Data collection was carried out from September to October 2011. The final sample consisted of $n=774$ respondents with the following demographic characteristics:

- $47 \%$ female and $53 \%$ male

- $\quad 0.4 \%$ of the sample completed compulsory education or less, $44 \%$ completed high school or vocational school and $55.6 \%$ completed higher education.

- Over $23 \%$ of participating employees were aged between 41 and 45 , followed by $22 \%$ of participants aged 46 to 50 . The smallest group of participants was aged up to $25(1.3 \%)$, followed by ages 26 to $30(6.1 \%)$ and over $56(7 \%)$.

- Measurements of health related absenteeism were performed using the same method as Ybema et al. (2010, p. 113) namely employees were asked two questions:

- how many days over the last 12 months were you absent from work due to health related reasons;

- $\quad$ how many times over the last 12 months were you absent from work due to health related reasons;

Measurements of abuse of medical leave (unethical behaviour) by employees were carried out using a question we developed ourselves. The question was posed as follows: "Were you absent from work for health related reasons over the last 12 months although you could have performed your work? « with a possible reply of "yes" or "no".

Within the scope of ethical behaviour we were also interested whether employees were present at work although they could have claimed medical leave due to illness or injury. This was established using the question »Have you in the last 12 months been present at work in spite of injuries or illnesses, because you felt the work had to be done?" with a possible reply of "yes" or "no".

\footnotetext{
${ }^{1}$ The main goal of the INODEL project was to "provide recommendations based on a dialog between social partners, actual working practice and scientific knowledge to provide social partners and policy implementors with an appropriate base for improving the state of affairs in the studied area. This would create greater awareness on the impact of the studied issues among the internal and external public, help reduce employee absence, contribute to employment and retaining of good employees, prevention of burnout in the workplace and aid in raising awareness of the importance and role of the family and its role in maintaining mental and physical health at work."

2 The study included the areas of stress and burnout in the workplace, health related absenteeism, fluctuation and coordination of professional and family life.

3 "Computer assisted web interview"
} 
Studying or measuring how employees perceive the honesty of management personnel was carried out using a question from the JSS (Job Satisfaction Survey) questionnaire of author Paul E. Spector. The original JSS questionnaire includes 36 questions divided into 9 areas (sections) used to establish job satisfaction. In our work on the present article we used a single question from the "management" section of the JSS questionnaire. The question used was »My superior is unfair towards me. "

In subsequent sections, the article first presents general data collected by studies within the INODEL project, and then presents results of the study of (un)ethical employee behaviour in the sense of abuse of medical leave and the correlation between the assessment of management personnel fairness by employees and absence of said employees.

\section{Results and Discussion}

The study aimed to verify or establish the state of affairs of employee absence and its correlation with factors that define the aspect of ethical behaviour of employees in their working environment.

Chart 1 presents the percentage of employees who were absent in the last 12 months. Results show that 48.5 of employees participating in the study were not absent from work in the last 12 months. Just over 33 percent of employees were absent for 1 to 10 days. 6.6 percent of participating employees were absent for over 30 days. ${ }^{1}$ Just over 33 percent of employees were absent for 10 to 30 days.

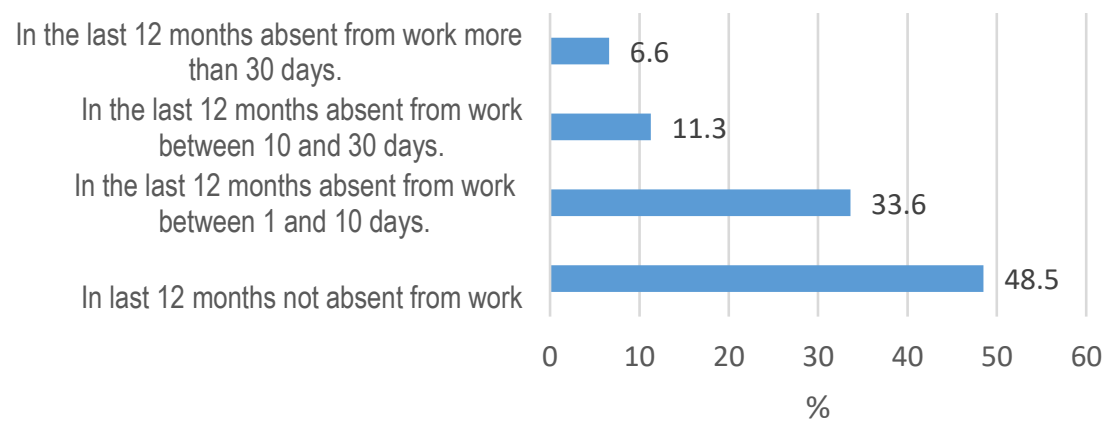

- Percentage of absence from work (\%)

Chart 1: Days of absence of employees from work over the last 12 months

Chart 2 shows that the majority of those absent in the last 12 months, were absent once. This accounted for 28 percent of absences. Just under 13 percent of participants were absent twice. 5.5 percent of participating employees were absent four or more times.

\footnotetext{
${ }^{1}$ Any absence over 30 days in the Republic of Slovenia means a financial cost for the Health Insurance Institute of Slovenia. Absences up to 30 days are a cost for the employer. Results of the study show that employers took on the financial cost of remuneration due to absence from work for just under 45 percent of employees who took part in the study and were absent for between 1 and 30 days.
} 


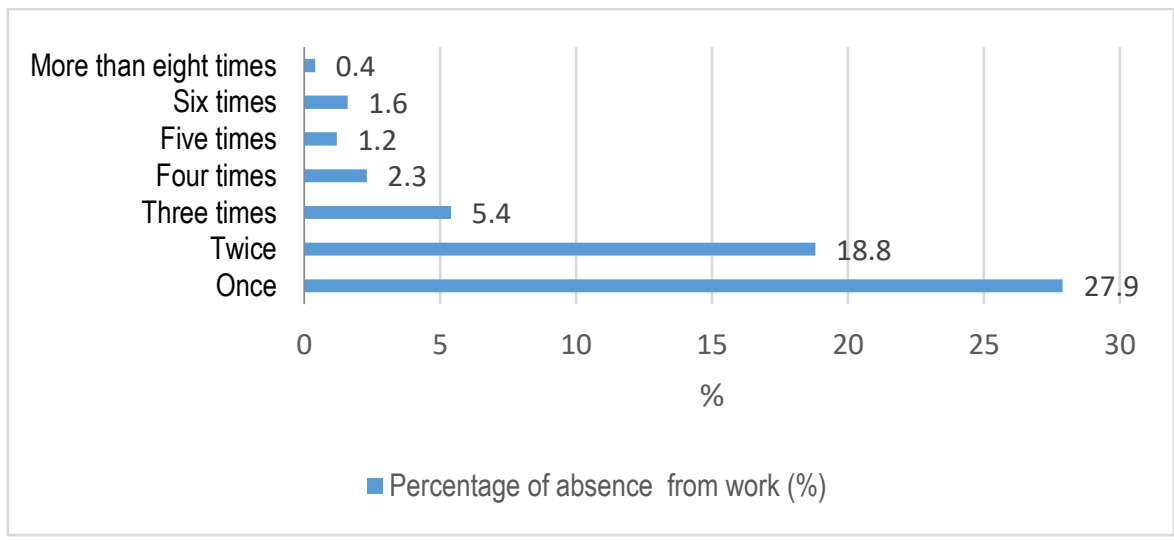

Chart 2: Frequency of absence of employees from work over the last 12 months

The study aimed to establish the moral and ethical attitude of employees to absence from work and whether employees "abused the option of medical leave/absence". Results in Chart 3 show that $9 \%$ of employees were on medical leave in the last 12 months although they could have performed their work. This result shows that there is a certain percentage of employees that for various reasons abuse the option of absence from work. On the one hand, such conduct (1) shows unethical behaviour and sets a poor example, while on the other hand (2) risking that such behaviour will be punished as it is not in accordance with the ethical attitude of employees.

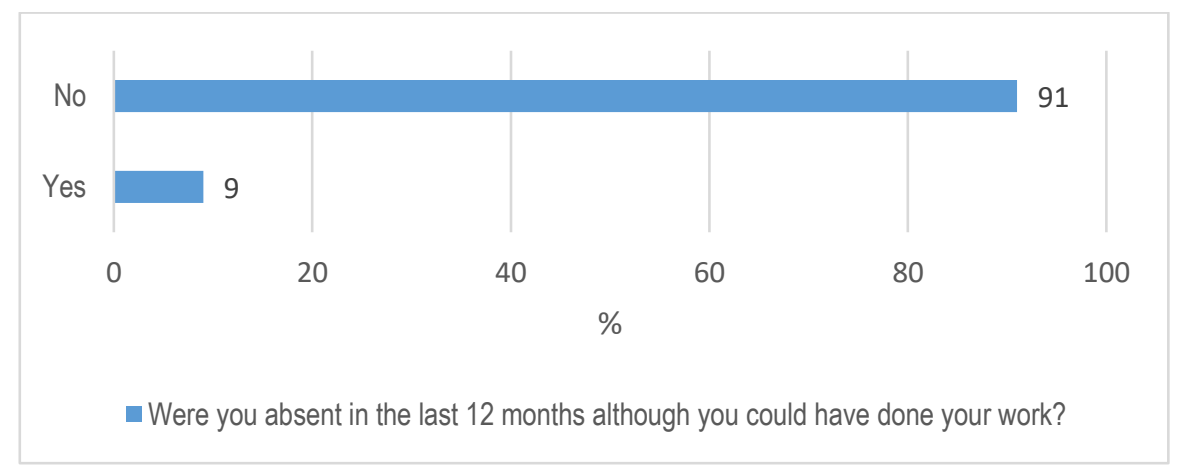

Chart 3: Abuse of medical leave in employees

The study also sought to establish whether employees performed their work in spite of illnesses or injuries that were in fact sufficient grounds for medical leave. Results in Chart 4 show that $75 \%$ of employees in the last 12 months performed their work in spite of injuries or illnesses that would warrant medical leave. The result can be interpreted in two ways, firstly as positive, as it shows moral and ethical responsibility/conduct of employees, and secondly as worrying as it shows signs of "presentism". 1

\footnotetext{
1 Presentism is a form of behaviour shown in employees coming to work in spite of illnesses or symptoms (malaise). The poor medical condition of such employees can in such cases be transferred to their colleagues (other employees), causing them to fall ill. Studies have shown that presentism is becoming more and more common. In the long term, presentism actually presents a greater financial cost than absentism.
} 


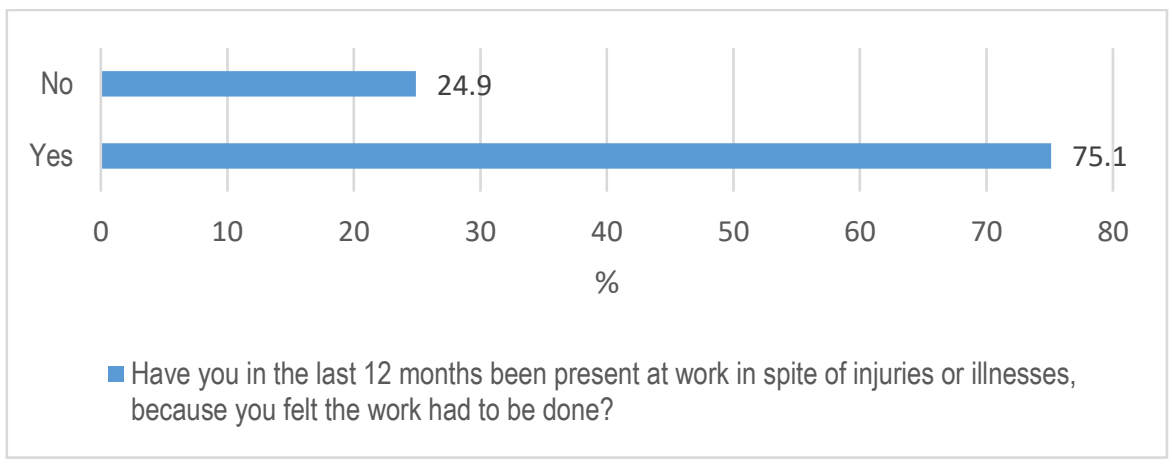

Chart 4: Performance of work in spite of illness or injury

The INODEL study researched the correlation between employee absence and their job satisfaction. Employee job satisfaction was measured using the JSS methodology tool. The "management" section of the study included the question "My superior is unfair towards me. "Results of this question showed that over $95 \%$ of those who were not absent from work felt that their superior was fair towards them, as did the majority of those absent between 3 and 30 days and even those absent for over 30 days.

In spite of this, statistical analysis shows that the variables "days of absence due to medical reasons" and "my superior is unfair towards me« have no correlation. That is why with a 5 percent risk we cannot state that there is a correlation between a fair attitude of management personnel and the number of days of employee absence. Such results regarding correlation therefore do not confirm the results of the study of De Boer et al. (2002, p. 181-197) which showed that a honest relationship with management personnel is reflected in a lower rate of employee absence. Honesty is one of the components of ethical behaviour.

Verification of hypotheses posed by the study shows the following:

- H1: Over 20 percent of employees that took part in the study were absent for medical reasons in the last 12 months, even though they could have performed their work.

Results of the study show that in a random sample over 20 percent of participants were absent for medical reasons in the last 12 months, even though they could have performed their work. The hypothesis is therefore not confirmed since statistical analysis shows 9 percent of such employees.

To test our hypothesis, we set the zero hypothesis $H_{0}: P=0.2$ against alternative hypothesis $H_{1}: P>0.2$. The sample share $=9 \%$ (see Chart 3 ) was used to calculate the value of $Z-3$. 84. The appropriate $P$ value is 0.99994 , which is higher than the risk rate of 0.05 . Accordingly, the zero hypothesis is kept and the alternative hypothesis is not confirmed. With a 5 percent risk we can therefore not state that the share of employees who were absent for medical reasons in the last 12 months, even though they could have performed their work, is greater than 0. 2 .

- H2: In the last 12 months, over 50 percent of employees that took part in the study continued to perform their work even though they experienced injuries or illnesses that could enable them to gain medical leave, because they felt and knew that is is appropriate for them to continue working.

- To test our hypothesis, we set the zero hypothesis $H_{0}: P=0.5$ against alternative hypothesis $H_{1}: P>0.5$. The sample share $=75.1 \%$ (see Chart 4 ) was used to calculate the value of $Z-5.80$. The appropriate $P$ value is $3,2 * 10^{-9}$, which is lower than the risk rate of 0.05 . Accordingly, the zero hypothesis is rejected and the alternative hypothesis is confirmed. At a 5 percent risk we can therefore state that the share of employees who in the last 12 months continued to perform their work even though they experienced injuries or illnesses that could enable them to gain medical leave, is greater than 0.5 .

- H3: There is a correlation between a fair attitude of management personnel and the number of days of employee absence. 
- To test our hypothesis, we set a zero hypothesis $\mathrm{H}_{0}$ : the variables »days of medical leave« and »my superior is unfair to me« anre independent towards the alternative $\mathrm{H}_{1}$ between variables »days of medical leave« and »my superior is unfair to me«.

Sample assessments for Kendalls Correlation and Spearman Correlation $\left(T=0.036, r_{s}=0.042\right)$ show that there is no correlation between the variables. Results were verified with statistical tests for both coefficients which showed that the variables indeed do not have any statistically significant corellation ( $p$ values: Kendalls, 249, Spearman, 248). This means that the zero hypothesis on the lack of correlation between the variables "days of absence due to medical reasons" and "my superior is unfair towards me« cannot be rejected, so the alternative cannot be confirmed. At a 5 percent risk we therefore cannot state that there is a correlation between a fair attitude of management personnel and the number of days of employee absence.

\section{Conclusions}

Organisational culture and its building blocks of norms and values is one of the most important constructs that influences the ethical behaviour of employees in an organisation. The latter is important as it provides answers on how to be and how to act. These issues are not merely external, so the issue of shaping and following work ethics and consequential ethical conduct of employees in an organisation is very important indeed. Employees in a working environment quickly percieve and accept a culture of conduct/behaviour and are often quick to adapt to it. For the purpose of this article, such an attitude is relevant also because if the culture of conduct/behaviour of employees pertaining to absence from work is such, that employees are often absent without justification or even abuse medical leave, and such behaviour is tolerated (e. g. the management shows no interest in attempting to reduce employee absence), such behaviour will be adopted by the majority of employees. Accordingly, it is very important that organisations establish an appropriate work ethic that provides for sanctions in case of inappropriate employee behaviour.

The influence of work ethics and consequential ethical conduct of employees is a correlate that is through its consequences shown also in the form of employee absence. Many studies have shown that a stronger (more strict) work ethic in an organisation results in a lower absence of employees from work. The results presented here are related to the aspect of (un)ethical conduct of employees in relation to medical absenteeism. Research performed within the INODEL study showed that at least 9 percent of participating employees have abused medical leave in the sense that they were able to work, but did not. This shows an (un)ethical attitude of employees and signals organisations that they need to pay more attention to work ethics and organisational culture. The result was no surprise - quite the opposite. It could be expected and we presume that many of our participants actually did not dare to answer that they previously abused their medical leave.

Results of the INODEL study also showed that the employees' perception of their management having an honest attitude towards them is in fact not reflected in a lower rate of employee absence, since the study did not show any statistically significant correlation. In spite of that fact, we found that over $95 \%$ of employees who were not absent from work in the last 12 months confirmed that their superior was fair to them. This result shows that employees perceive honesty as a positive thing which in turn results in a lower degree of absence, bringing direct financial gains to the organisation.

Based on the results presented above we can see that work ethics and an appropriate organisational culture do influence - increase or reduce the rate of employee absence.

\section{References}

[1] Allebeck, Peter \& Mastekaasa, Arne. (2004). Causes of sickness absence: research approaches and exlanatory models. Scandinavian Journal Public Health, 32 (63), 36-43.

[2] Briner, Rob B. (1999). Absence from work. BMJ - Education and debate, 15, 873 - 879.

[3] Cummings, G. T. \& Worley, G. C. (2001). Organizational Development \& Change (7th ed. ). Ohio: South - Western College Publishing. 
[4] De Boer, E. M. , Bakker, A. B. , Syroit J. E. \& Schaufeli, W. B. (2002). Unfairness at work as a predicator of absenteeism. Journal of organizational behavior, 23, 181-197.

[5] Eggert, Max A. (2009). Absence Management Pocketbook. Management Pocketbooks LTD, Alresford.

[6] Evans, Alastair \& Palmer, Steve (2000). From absence to attendance. Chartered Institute of Personnel and Development - CIPD House, London.

[7] Fitzgerald, G. A. \& Desjardins, N. M. (2004). Organizational Values and their relation to organizational perfomance outcomes. Atlantic journal of communication, 12 (3), 121-145.

[8] Gardiner, Richard C. (1992). Tracking and Controlling Absenteeism. Public Productivity \& Management Review, 15 (3), 289-307.

[9] Guerts, s. , Bunk, A. P. , \& Schaufeli, W. B. (1991). Absenteeism seen from a social comparison perspective. Gedrag \& Organisatie, 4, 385-398.

[10] Løkke, Ann-Kristina, Eskildsen, Jacob K. , \& Jensen, Troels Wendelboe (2007). Absenteeism in the Nordic countries. Employee Relations, 29 (1), 16-29.

[11] Martocchio, Joseph J. , Jimeno, Diana I. (2003). Employee absenteeism as an affective event. Human Resource Management Review, 3, 227 - 241.

[12] Moorhead, G. \& Griffin, R. W. (1998). Organizational behavior: managing people and organizations. Boston: New York: Hougton Mifflin.

[13] Musek, J. (1993). Znanstvena podoba osebnosti. Educy d. o. o. , Ljubljana, 1993.

[14] Prottas, David J. (2008). Perceived Behavioral Integrity: Relationships with Employee Attitudes, Well-Being, and Absenteeism. Journal of Business Ethics, 81, 313-322.

[15] Rozman, R. , Kovač, J. \& Koletik, F. (1993). Management. Gospodarski vestnik, Ljubljana.

[16] Rubin, J. Z. , Pruitt, D. G. \& Kim S. H. (1994). Social Conflict: Escolation, Stalemate, and Settlement. McGraw-Hill, New York, NY.

[17] Sanders, K. (2004). Playing truant within organisations: informal relationships, work ethics and absenteeism. Journal of managerial psychology, 19 (2), 136-155.

[18] Savery, Lawson K. , Travaglione, Anthony \& Firns lan G. J. (1998). The links between absenteeism and commitment during downsizing. Personnel Review, 27 (4), 312-324.

[19] Van Dierendonck, D. , Pascale, M. \& Van Breukelen, W. (2002). Supervisory behavior, reciprocity and subordinate absenteeism. Leadership \& Organization Development Journal, 23 (2), 84-92.

[20] Van Yperen, N. W. , Hagedoorn, M. \& Guerts, S. A. (1994). Withdrawal of employees: leaving and absenteeism as a raaction to unfairness. Gedrag en Organisatie, 7, 5-19.

[21] Ybema, Jan F. , Smulders, Peter G. W. \& Bongers, Paulien M. (2010). Antecedents and consequences of employee absenteeism: A longitudinal perspective on the role of job satisfaction and burnout. European journal of work and organizational psychology, 29, 102-124. 